Arteterapia. Papeles de arteterapia y educación para inclusión social ISSN-e 1988-8309

http://dx.doi.org/10.5209/ARTE.57560

\title{
Ser en el arte: caminos de reconocimiento
}

\author{
Liliana Otero Caicedo ${ }^{1}$; Aleida Fernandez Moreno ${ }^{2}$
}

Recibido: 08 de diciembre de 2016 / Aceptado: 21 de julio de 2017

Resumen: Esta vivencia investigativa tuvo como propósito generar reflexiones creativas, sentidas y encarnadas en torno a las experiencias de reconocimiento que las personas con dis_capacidad de la Fundación Luna Arte viven en sus recorridos artísticos desde la perspectiva de Axel Honneth. Estas reflexiones, nacen desde los cuerpos metaforizados en los body maps que se enmarcan en la Investigación Basada en las Artes como metodología del estudio. Se concluye principalmente que el disfrute y la participación en la vida artística contribuye a la estima social de esta población y, por ende, al realce de sus capacidades, cualidades y a la valoración de sus aportes dentro de su comunidad.

Palabras clave: Arte, dis_capacidad, Ética del Reconocimiento, experiencias de reconocimiento.

\section{[en] Be in art: ways of recognition}

Abstract: This research experience was intended to generate creative reflections, felt and embodied around the experiences of recognition that people with dis ability Moon Art Foundation live in their artistic journeys from the perspective of Axel Honneth. These reflections are born from the metaphorized bodies in body maps since the Arts-based Research as study methodology. It mainly concludes that the enjoyment and participation in the artistic life contributes to social esteem of this population and therefore the enhancement of their skills, qualities and valuation of their contributions within their community.

Keywords: Art, disability, Ethics of Recognition, experiences of recognition.

Sumario: 1. Preludio. 2 Pinceladas sobre la teoría del reconocimiento desde Axel Honneth. 3. Escenario para co-crear e investigar narraciones sentidas. 4. El arte, una experiencia para trasformar y transformarse, 5. Voces de colores que emergen desde el cuerpo. 6. Tertulia Reflexiva. 7. Finalizando el recorrido para andar nuevos caminos. 8. Referencias Bibliográficas.

Cómo citar: Otero Caicedo, L.; Fernández Moreno, A. (2017). Ser en el arte: caminos de reconocimiento, en Arteterapia. Papeles de arteterapia y educación para inclusión social 12, 25-42.

\footnotetext{
$1 \quad$ Universidad de Nariño

leoteroc@unal.edu.co

2 Universidad Nacional de Colombia

cafernandezm@unal.edu.cos
} 


\section{Preludio}

Este entretejido reflexivo se propone en torno a las intersecciones que se urden entre el Arte, el Reconocimiento y la Dis_capacidad ${ }^{3}$, que si bien pueden sospecharse muchas veces se subestiman. Lo que presentamos a continuación es una experiencia musicalizada con innumerables reflexiones, pasos vaciados de aprendizajes, dudas acuciantes y tropiezos recurrentes. En la memoria de estas páginas se hila un tejido vivo que emerge desde el cuerpo y rescata la emocionalidad, la afectividad, la sensibilidad y la creación como un conocimiento legítimo que puede agenciar metamorfosis sociales.

\section{Pinceladas sobre la teoría del reconocimiento desde Axel Honneth ${ }^{4}$}

Comenzaremos por decirles que el concepto de reconocimiento tiene gran relevancia para considerar una perspectiva ética y política del arte y la dis_capacidad, pues "en la ética antigua, era sobresaliente la convicción de que sólo podía llevar una vida buena aquella persona cuyo modo de actuar pudiera encontrar estimación social dentro de la polis" (Honneth, 1998: 20). La noción de reconocimiento que plantea Honneth (1997) cobra vida a partir de los escritos del joven Hegel en los cuales afirma que la estructura de la relación de reconocimiento recíproco se refiere a que: "un sujeto deviene siempre en la medida que se sabe reconocido por otro en determinadas de sus facultades y cualidades" (p. 28) y es la reclamación de las personas de un reconocimiento intersubjetivo la que buscan para la realización de sus vidas, por lo cual, están sujetas al respeto o la estimación que les brindan los otros y otras en la interacción.

Así, con base en los escritos tempranos del joven de Hegel, Honneth (1998) concluye que "los sujetos humanos sólo llegan a una autorreferencia intacta al verse reconocidos o confirmados en el valor de determinadas capacidades y derechos" ( $p$. 32). Por ello, reconocer a una persona en una determinada dimensión de su integridad personal implica efectuar acciones, asumir responsabilidades y adoptar actitudes que le permitan alcanzar la correspondiente comprensión de su propia persona. Por otra parte, el autor también resalta el hecho de que las ofensas o heridas que devengan de un no reconocimiento, pueden generar la motivación en los seres humanos para luchar y lograr reivindicaciones morales.

Teniendo en cuenta lo anterior, Honneth realiza una organización tripartita basándose en los postulados del joven Hegel. De manera que, el pensador alemán plantea tres formas o esferas de reconocimiento en las cuales "quedan mencionadas las actitudes morales que tomadas en su conjunto constituyen la posición que, una vez adoptada, asegura las condiciones de nuestra integridad personal" (Honneth, 1998: 33).

Utilizamos el guión bajo para separar el prefijo dis. Seguiré utilizando esta escritura, pues este es un símbolo que más que separación significa ruptura lo que precisamente buscamos develar en el arte como un hacer ético, una ruptura entre el prefijo dis (anulación) y la palabra capacidad.

4 Filósofo y sociólogo alemán, considerado como una de las figuras más importantes de la llamada tercera generación de la Escuela de Frankfurt, reconocido por sus investigaciones en la teoría del reconocimiento y seguidor de la tradición de la Teoría crítica de la sociedad. 


\section{Esfera del Amor}

Por relaciones amorosas deben entenderse según Honneth (1997) "todas las relaciones primarias, a ejemplo las relaciones eróticas entre dos, las amistades o las relaciones padres-hijos que estriban en fuertes lazos afectivos" (p. 118). Para Honneth (1997), el amor representa el primer estadio de reconocimiento recíproco, en el cual las personas se reconocen como entes de necesidad y dependientes entre sí en la experiencia recíproca de atención amorosa. Este tipo de reconocimiento tiene el carácter de una dedicación afectiva, lo que implica un interés por el bienestar de otro por sí mismo. Dado esto, los sentimientos desplegados recíprocamente proporcionan una valoración específica, en la que las y los sujetos llegan a una confianza en sí mismos y en sí mismas, traducida fundamentalmente en una seguridad emocional, no sólo en la experiencia intersubjetiva del amor, sino también, en la exteriorización de las propias necesidades y sentimientos. Teniendo en cuenta esto, consideramos que es importante reflexionar en torno al papel de la creación artística que una persona con dis_capacidad desarrolla, en las relaciones con su familia, amistades y cómo dicha creación posibilita configurar lazos afectivos que favorezcan la expresión de las necesidades y sentimientos de la persona, y así, llegar a vivir experiencias de reconocimiento que forjen una confianza en ella misma.

\section{Esfera de la Ley}

Retomando los postulados de Hegel y Mead, reconocerse recíprocamente como persona de derecho, actualmente significa "no sólo la capacidad abstracta de poder orientarse respecto de normas morales, sino también la capacidad concreta de merecer la medida necesaria en nivel social de vida por la que un sujeto es entretanto reconocido cuando encuentra reconocimiento jurídico" (Honneth, 1997: 144). Entonces resulta que la conquista que se alcanza en las relaciones de derecho es poder respetarse a sí mismo o a sí misma debido a que merece el respeto de los demás. Por lo tanto, se puede hablar de la responsabilidad moral como núcleo digno de respeto de una persona; porque sólo en condiciones en que los derechos individuales se reconocen en tanto hombres y mujeres libres, la persona puede ver, en ella reconocida, su capacidad de juicios autónomos. Es aquí donde gana el autorrespeto.

En este punto anotamos que, según Palacios (2008) la dis_capacidad "es una categoría social y política en cuanto implica prácticas de las regulaciones y las luchas por la posibilidad de elección, potenciación de los derechos" (p. 175) y es por esto que se plantea la necesidad de ser abordada desde las dinámicas del reconocimiento. Dentro de este marco, las personas con dis_capacidad están cada vez más comprometidas en el desafío de estereotipos decretados por el poder hegemónico y en el desarrollo de unas ideas dignas y alternativas, que reconozcan la dis_capacidad como una cuestión de derechos humanos, especialmente en la interacción de las personas con las instituciones.

En este contexto, el arte se constituye como un derecho para las personas con dis_capacidad, dado que en el artículo 30 de la Convención de los Derechos de las Personas con Discapacidad se reconoce el derecho de dichas personas a participar, en igualdad de condiciones con las demás en la vida cultural, asegurando que puedan desarrollar y utilizar su potencial creativo, artístico e intelectual, no sólo en su propio beneficio sino también para el enriquecimiento de la sociedad, y garantizando que a) tengan acceso a material cultural en formatos accesibles, b) Tengan acceso a programas de televisión, películas, teatro y otras actividades culturales en formatos 
accesibles, c) tengan acceso a lugares en donde se ofrezcan representaciones o servicios culturales tales como teatros, museos, cines, bibliotecas y servicios turísticos y, d) en la medida de lo posible, tengan acceso a monumentos y lugares de importancia cultural nacional (Palacios y Bariffi, 2007: 119). Es así como, el arte, ha de considerarse según Mabila (2002) como una herramienta política vital para elevar el nivel de conciencia acerca de los derechos de las personas con dis_capacidad, pues cuando las personas con dis_capacidad se representan a sí mismas, se están enfrentando a la tradición que es representada por otros y otras para cambiar actitudes negativas y representaciones incorrectas frente a su condición y dar paso a la vigencia de sus derechos.

\section{Esfera del logro}

Esta esfera hace referencia a la apreciación social del rendimiento y de las capacidades individuales (Honneth, 2011). Para Honneth (1997) los seres humanos "necesitan más allá de la experiencia de la dedicación afectiva y del reconocimiento jurídico, una valoración social que les permita referirse positivamente a sus cualidades y facultades concretas" (p. 148). De esta manera, las capacidades y actuaciones de las personas pueden ser intersubjetivamente estimadas en la medida en que su forma de autorrealización contribuye a la consecución práctica de los objetivos definidos de la sociedad. Por lo tanto, según el autor "el horizonte general de valoración establecido por una comunidad debe permanecer abierto a los diferentes tipos de autorrealización" (p. 155); en otras palabras, la consideración social de las personas se configura en las capacidades individuales que aportan en el marco de sus formas particulares de autorrealización.

Desde esta perspectiva, las relaciones internas en una comunidad específica adoptan el carácter de relaciones solidarias; por medio de las cuales, las personas se valoran entre sí de forma simétrica lo que significa que todos los seres humanos tienen la oportunidad de sentirse en sus propias capacidades como valiosos para la sociedad, sin olvidar que sólo en la medida en que yo activamente me preocupo de que el otro u otra pueda desarrollar sus propias cualidades, pueden realizarse los objetivos que nos son comunes, y es así como, la experiencia de la valoración social lleva finalmente a la conquista de la autoestima. (Honneth, 1997, 1998). No obstante, consideramos importante mencionar que Honneth (2011) afirma que la apreciación social de una persona se mide según su aportación a la sociedad en forma de un trabajo formalmente organizado.

Sin duda, creemos que las personas con dis_capacidad itinerantes en recorridos artísticos encuentran escenarios creativos y sensibles que posibilitan la valoración social de sus capacidades, aunque esto rara vez se visibiliza fuera de un contexto terapéutico. Así, es necesario resaltar que el arte, es una oportunidad para politizar los temas relacionados con la dis_capacidad, teniendo en cuenta que la ausencia de imágenes positivas de personas con dis_capacidad en el mundo del arte, refleja las actitudes dominantes desde las cuales se percibe a la gente diferente como problemas religiosos, morales, políticos y económicos por la sociedad (Mabila, 2002). 


\section{Escenario para co-crear e investigar narraciones sentidas}

Antes de continuar, queremos contarles acerca del lugar lleno de magia y color que fue cómplice de estos recorridos investigativos. Esta vivencia investigativa tuvo lugar en la Fundación Luna Arte ONG sin ánimo de lucro ubicada en la ciudad de Pasto (Colombia) que desde el 2004, está encaminada a generar procesos para el desarrollo de la capacidad individual y colectiva, basados en la interrelación dinámica y continua entre el arte, el afecto y la autoexpresión como sus principales ejes, mediante herramientas artísticas aplicadas en espacios culturales y sociales para dinamizar una propuesta alternativa de desarrollo humano integral para la vida de niños, jóvenes y adultos sin y con dis_capacidad. Todo esto, teniendo en cuenta que el arte es concebido como una necesidad y un derecho humano que garantiza el acceso a los bienes simbólicos y a la producción universal de sentido con identidad; que clarifica e ilumina nuestras experiencias colectivas pasadas, presentes y futuras. De manera que, el arte empodera, provoca y genera relaciones más democráticas e igualitarias y es considerado un fin y un medio en la construcción de las subjetividades.

Ahora bien, fueron cinco las personas que no sólo hicieron parte de este estudio, sino que le dieron vida y posibilitaron encuentros de creación conjunta donde el arte fluía y entretejía vivencias y experticias. Ellos y ellas decidieron para este estudio llamarse Marcela, María, Fabián, Hugo y Jesús; personas quienes viven y experimentan día a día diferentes situaciones de dis_capacidad y que pertenecen a la Fundación desde hace más de cinco años. Estos increíbles seres humanos cuentan con una amplia trayectoria artística dentro del campo de la pintura, la danza, el teatro y la música lo que los y las ha llevado a participar de innumerables eventos culturales en el Departamento de Nariño y a ser reconocidas y reconocidos como actores culturales que propician la inclusión social y crecimiento de las tradiciones culturales del Departamento. Así que, es menester expresar nuestro total y profundo agradecimiento a estos seres creativos y amorosos quienes le dieron vida a esta investigación. Gracias a muestros compañeros y compañeras de viaje por compartir sus experiencias y abrir su corazón para disfrutar de la exploración artística que juntos vivimos. Ellos y ellas son los co-creadores de esta historia. Y por supuesto, agradecimientos sinceros a la Fundación Luna Arte, a su directora Sonia Miranda y talleristas: Oscar, Jorge, Baldomero, Magda, Tika por su apoyo incondicional sin el cual esta investigación no habría sido posible.

\section{El arte, una experiencia para trasformar y transformarse}

Los caminos que pintamos de manera conjunta con los y las creadoras del estudio, se enmarcaron en la Investigación Basada en las Artes (IBA), la cual, según la postura de Springgay, Irwiny Wilsonz (2005) no debe ser entendida como una extensión de la investigación cualitativa, a pesar de emerger de las líneas más arriesgadas y extremas de ésta, sino que, por el contrario, debe considerarse como un paradigma diferente en tanto que presenta diversas novedades metodológicas que provocan un desplazamiento hacia un territorio nuevo e independiente. Esto implica ir más allá de la utilización de criterios actuales que existen en la investigación cualitativa y abrazar rupturas, cambios y ausencias que configuran el desarrollo de otros cursos de acción con y desde el arte. 
Quisiéramos resaltar que la IBA, es una investigación viva, es una indagación que se respira, que se escucha $\mathrm{y}$, por lo tanto, sentida que provoca rupturas que abren nuevas maneras de concebir la construcción de conocimiento (Springgay et al., 2005). Además, busca otras maneras de mirar y representar las experiencias y plantearnos cuestiones que otras maneras de hacer investigación no nos plantean, ya que las artes, llevan el hacer al campo de la investigación y posibilitan acceder a lo que las personas hacen y no sólo a lo que dicen. En este sentido, este tipo de investigación no persigue las certezas, las explicaciones sólidas ni las predicciones confiables, sino el realce de perspectivas, señalización de matices y lugares no explorados que develen otras maneras de ver los fenómenos, debido a que esta es una investigación más sensible a las cualidades sensoriales de los fenómenos y situaciones que se estudian, lo que trasforma creativamente tanto el propósito, como el desarrollo y los resultados de la investigación (Marín, 2011).

De ahí que, ésta se convierta en una investigación sobre nuestras vidas y se requiere los órganos, las mentes y las emociones para construir sentidos a través de los sentidos (Roldan \& Marín, 2012). Según lo anterior, este tipo de metodología permite afianzar una coherencia con la postura ética y moral que, desde mi punto de vista, permea el arte, pues rescata la emocionalidad, la sensibilidad y la creación como un conocimiento legítimo que provoca la reivindicación social, el resurgimiento de subjetividades creadoras y el reavivamiento de formas diversas de situarse en el mundo.

Les contamos que, el proceso de co-creación e investigación que propusimos en este estudio parte de la creación de narraciones visuales y textuales las cuales se pondrán en escena a través del bodymap (retomamos esta denominación para la investigación) como el arte-facto que hiló el entramado de construcciones sensibles, sensoriales, emocionales, corporales, dinámicas, interactivas e intersubjetivas que implicaron un posicionamiento ético y moral en torno a las experiencias de reconocimiento que viven las personas con dis_capacidad en sus recorridos artísticos. Les comentamos con mayor detalle en qué consiste esta estrategia.

El bodymap se originó en el sur de África para contrarrestar el estigma y el miedo por el reconocimiento de las historias de vida de mujeres con VIH y SIDA. Éste se define como imágenes de nosotros o nosotras mismas plasmadas en el dibujo del cuerpo humano de tamaño real. El bodymap como "instrumento" o "técnica" de investigación ofrece una metáfora para reconocer los trazos personales de experiencias sociales, políticas, emocionales que se recogen en el camino de una vivencia; es decir, aspectos éticos y morales que, en este caso en particular, se enmarcan en las dinámicas de reconocimiento vividas por las personas que pertenecen a la Fundación Luna Arte de la ciudad de Pasto. En estos mapas corporales se cristalizan imágenes de vida que se han desarrollado dentro de los contornos del cuerpo y representan el sentir frente a una experiencia de vida. Asimismo, dichos mapas son capaces de aumentar la conciencia, llamar la atención acerca de las diferentes cuestiones política, personal y social que vive una persona o personas en un escenario particular y contribuir de esta manera a su redefinición (Gastaldo et al., 2012). 


\section{Voces de colores que emergen desde el cuerpo}

Las narraciones que les presentamos en este apartado nacen de los encuentros afectivos, enmarcados dentro de la creación artística, entre seres humanos que pintan experiencias tejidas a lo largo de sus vidas, las cuales les han significado su propia configuración como sujetos y sujetas que sienten, viven, y crean. Estos encuentros abrieron paso a una investigación-creación compartida en la cual todas y todos fuimos creadores y co-investigadores y fuimos quienes hilamos vivencias encarnadas para transformarlas en una gran trama de conocimiento académico centrado en el sentir, el afecto y la creación artística. De manera que, el tejido que exponemos a continuación es una elaboración conjunta basada en expresiones artísticas que dieron lugar a un diálogo evocado por el trabajo con los bodymaps que posibilitó desatar lecturas empáticas e intersubjetivas para reflexionar en torno a las dinámicas de reconocimiento que enfrentan las personas con dis_capacidad itinerantes por rutas artísticas.

Quisiéramos anotar que, mi interés en esta investigación fue que las voces de las personas participantes sean las protagonistas en el proceso de co-investigación-creación. Por lo tanto, las narraciones emergen de un diálogo permanente entre él o la autora de la creación y la investigadora. En otras palabras, lo que buscamos con este tipo de estrategia metodológica, no fue realizar una interpretación del significado de las imágenes consignadas en el bodymap por parte de una psicóloga, sino que, por el contrario, que las personas participantes en este estudio narren aquello que se estaba plasmando en su propio bodymap y fueran ellas y ellos quienes configuraran su significado. De esta manera, lo que aquí se presenta son las narraciones que emergen desde los bodymaps en torno a las experiencias de reconocimiento y expresadas por los y las participantes en forma de poesías dadaístas para conservar el protagonismo de su voz como ya lo mencionamos anteriormente.

En concordancia con los caminos que se buscaban pintar con esta investigación guiados por los objetivos planteados, presentamos en una fotografía los relatos que encarnan los bodymaps a partir de técnicas basadas en las artes como: el dibujo, pintura, collage, escritura y que configuran las experiencias de reconocimiento que viven las personas participantes en este estudio.

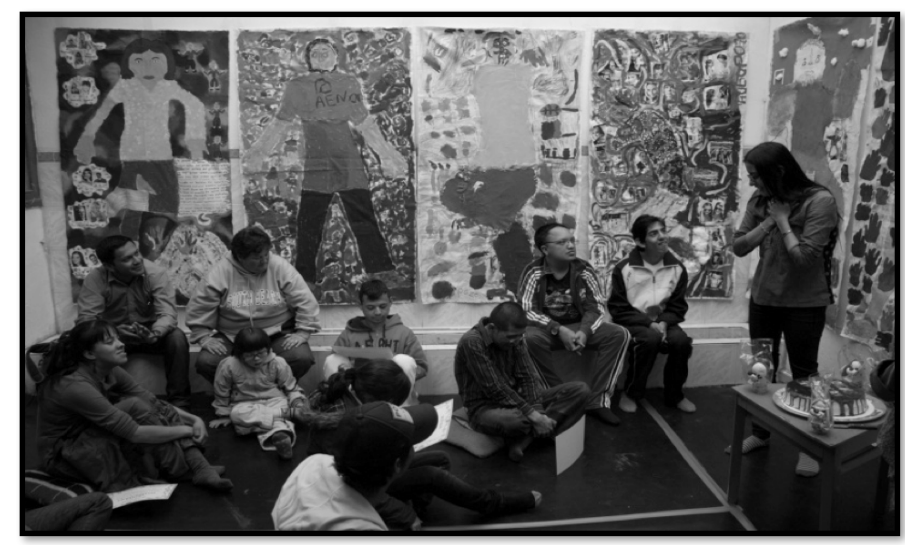

Imagen 1. Presentación de los Bodymaps. Dibujos del cuerpo en tamaño real de los y las artistas elaborados de la pintura, el collage y la escritura. 
Experiencias de reconocimiento, esferas del amor, ley y logro

Las experiencias de reconocimiento como generadoras de una valoración positiva en la que las y los sujetos consolidan una confianza en sí mismos y en sí mismas, traducida fundamentalmente en una seguridad emocional dada por la experiencia intersubjetiva del amor, en este estudio estuvieron enmarcadas por las relaciones con la familia, los amigos, la pareja y las instituciones (la Fundación), así como también, con las relaciones con la sociedad en general que se hacen visibles en la participación de tradiciones culturales como es el Carnaval de Negros y Blancos ${ }^{5}$ de la ciudad de San Juan de Pasto. Los poemas dadaístas $^{6}$ en colores que acompañan el texto y que emergen de la creación de los bodymaps, son las narraciones de las personas que participaron en la investigación con la intensión de que su voz sea siempre la protagonista.

Mi familia...

Dicen que mis dibujos son bonitos (Hugo)

Que aproveche y siga como pintor (Hugo)

Mi hermana, ella sí me apoya (Jesús)

Mi primo me dijo: sos un berraco...me ganaste a mí (Jesús)

Oscar, Yoyo, Mamá Sonia (Hugo)

Me dicen que están bonitos mis dibujos (Marcela)

Tía, tío, primo, sobrino, prima, cuñada, sobrina, suegra, novia (Hugo)

Me dicen que están bonitos mis dibujos (Marcela)

Mi mamá me colabora mucho (Marcela)

Mi hermano me paga la matrícula (Marcela)

Mi hermano me dijo: yo le doy la pensión (Jesús)

\author{
Me apoyan (Hugo) \\ Mi hermana paga la matrícula (Hugo) \\ A mi familia les gustan mis trofeos (Hugo) \\ Mi familia me apoya (María)
}

Figura 1. Poema dadaísta esfera del amor

\title{
Esfera de amor: Relaciones familiares
}

En las narraciones textuales de las personas que participaron en los encuentros vivenciales: Hugo, Jesús, Fabián, Marcela y María surgen las relaciones con la madre, hermanos y hermanas, primos, los docentes y directora de la Fundación. Estas relaciones se tejían con el apoyo, la colaboración, la admiración y la credibilidad en el trabajo artístico que realizan en la Fundación y cómo éste puede constituirse en una oportunidad para alcanzar la autorrealización. También se percibió el aporte económico en lo que se refiere al pago de la matrícula que los vincula directamente con la Fundación un apoyo relevante.

Es interesante observar que algunas palabras expresadas por la familia se constituyen en actos de reconocimiento para las personas con dis_capacidad y además son un impulso para continuar con más fuerza en su trabajo debido a la confianza que a partir de ellas se configura.

Carnaval de Negros y Blancos tradición cultural Nariñense, específicamente del municipio de San Juan de Pasto declarado en el 2009 Patrimonio Cultural Inmaterial de la Humanidad por la UNESCO.

6 Los y las dadaístas tomarían, dentro de la poesía, el principio del azar como una nueva forma de creación artística, un elemento espontáneo que dotaría al arte de un nuevo contenido trasgresor frente a principios lógicos de creación artística, invocando una revolución, una nueva experiencia(Burgos, 2009). Para realizar una poesía dadaísta se recortan palabras, se las coloca en un bolsa plástica, se la agita y posteriormente se sacan palabras al azar que colocadas en su orden de escogencia forman el poema. 
Es importante también resaltar cómo se empieza a visualizar el trabajo artístico realizado en la Fundación y se perfila, en este caso para la madre de Marcela (según relato de Marcela), como una oportunidad para lograr la autonomía. En el caso de los premios, es posible señalar que pueden constituirse como experiencias de reconocimiento para Hugo y Jesús, en este caso en particular. Por otra parte, es importante destacar que Oscar, Jorge (profesores de la Fundación) y "Mamá Sonia" (denominación a la directora) son considerados como parte de la familia.

\author{
Mis amigos y amigas \\ Me apoyan (Hugo) \\ Les gusta que dibuje (Hugo) \\ Les gustan mis pinturas (Jesús) \\ Participamos en las comparsas (María) \\ Quieren ver dónde trabajo (Hugo) \\ Que haga cuadros para vender (Hugo)
}

Todos buscan la solución a nuestros problemas (Marcela)

Dicen que siga dibujando (Hugo)

Oscar, Yoyo y Baldomero (Hugo)

Buscan que yo esté bien (Marcela)

Son parte de la familia (Marcela)

Salgo con mis amigos en el carnaval (Fabián)

Salimos a bailar (Marcela)

Mis amigos me aceptaron (Marcela)

Figura 2. Poema dadaísta esfera del amor

La Fundación Luna Arte

Esfera del amor:

Relaciones de amistad

Las relaciones que las jóvenes y los jóvenes establecen con sus amigos y amigas son vitales en sus experiencias de reconocimiento, pues sin duda aquellos vínculos urden hilos de apoyo, interés y confianza en el hacer artístico (que se traduce en las palabras como "bonito" y en el interés de comprar dichos haceres y quizá configurar una opción laboral); en el disfrute de actividades como el salir a bailar, la participación conjunta en diferentes espacios como es el Carnaval y en la búsqueda del bienestar.

Cabe resaltar que, estas relaciones tejidas en la cotidianidad del hacer artístico están permeadas por la aceptación de la persona. Las amistades que emergen en el diario vivir de la creación artística en la Fundación son de mucha importancia para las personas de este colectivo.
Escogí el color tomate porque es el de la Fundación (Hugo)

Donde vamos está el beso, el abrazo (Marcela)

Me quedo aquí así me haga viejo (Jesús)

Yo entré a la Fundación y cambió mi vida (Jesús)

Ahora recibo amor, cariño y respeto (Marcela)

He llegado hasta aquí por su amor y cariño (Marcela)

Le pregunto al profe si le gusta mi trabajo (Hugo) Mi vida cambio cuando entré a la Fundación (Marcela)

En la Fundación me siento como en mi casa (Jesús)

Se dan cuenta (Marcela)

Somos personas con capacidades diferentes (Marcela)

Mi camiseta es del color de la Fundación (Hugo)

Aquí encontré personas que de verdad valemos (Marcela)

Profe mire mi trabajo!! (Hugo)

Yo le agradezco a Sonia que haya llamado a mi mamá (Jesús)

Se siente la importancia de ellos a nosotros y de nosotros a ellos (Marcela)

Gracias a Sonia descubrí que puedo (Marcela)

Figura 3. Poema dadaísta esfera del amor 
Son los amigos y amigas quienes brindan apoyo, aliento, confianza y con quienes se puede disfrutar las actividades cotidianas de la vida. Sin embargo, los amigos no son sólo las personas con las que se disfrutan sino las que se preocupan por el bienestar del otro o de la otra, quizá por esta razón Marcela menciona que "hacen parte de la familia". Es interesante cómo las manifestaciones artísticas y culturales, entre ellas el carnaval, favorecen la creación y el fortalecimiento de estas relaciones de amistad basadas en el afecto y en la aceptación.

Por otra parte, reaparecen los docentes de la Fundación quienes bajo ninguna circunstancia se perciben como profesores sino como esos maestros de vida que son amigos y familiares a la vez. Es interesante que el hacer artístico, en este caso el de Hugo, emerja como una oportunidad laboral.

\section{Esfera de la ley: Relaciones Institucionales}

Por otra parte, en lo que tiene que ver con las relaciones de carácter institucional se presentan las que se entretejen con la Fundación y las personas que las conforman, es decir, el colectivo de personas con dis_capacidad que participó en este estudio. Estas relaciones sin duda se tejen a partir del afecto encausado a través de los procesos de creación artística que posibilitaron un giro existencial en la vida de estas personas quienes encuentran en el amor, cariño y apoyo, el camino para llegar a ganar el autorrespeto al recibir el respeto de los demás, pues gracias a las experiencias que viven en la Fundación se perciben como sujetos con capacidades que valen como seres humanos.

Fue significativo encontrar en las narraciones de las personas con dis_capacidad que sus vivencias en la Fundación son esenciales en su vida, de ahí que, todos y todas dibujaron o mencionaron temas alusivos a la organización y al trabajo que sus integrantes realizan allí, por ejemplo, el dibujarse y pintarse con los colores de la camiseta que los identifica como parte de la Fundación y, junto con esto, las evidentes frases de Jesús que evidencian su sentido de pertenecía "de aquí no me saca nadie, ni el gobierno ni la iglesia (Jesús)". Además, lo que experimentan día a día dentro de paredes llenas de colores brillantes y formas sorprendentes son expresiones de cariño, afecto, apoyo y respeto que los lleva a sentirse valorados y valoradas. De igual manera, consideramos importante señalar que los maestros se constituyen en catalizadores de experiencias de reconocimiento en la medida en que sus apreciaciones frente a los haceres artísticos y su interés frente a situaciones personales de los participantes establecen factores que les hacen percibirse como seres humanos igualmente valiosos. En otras palabras, quizá sin advertirlo, y de manera natural, los y las maestras asumen una responsabilidad moral frente al respeto de este colectivo de personas.

\section{Esfera del logro: Relaciones con el contexto social: Participación y apreciación de capacidades}

Lo que nace de las narraciones textuales y visuales de los y las co-investigadoras hacen referencia a las relaciones con el contexto que tienen que ver con la participación en eventos de tradición cultural como el Carnaval de Negros y Blancos y en diferentes prácticas artísticas como el teatro y la pintura; escenarios creativos y sensibles que posibilitan la apreciación de sus capacidades. Estas relaciones también se materializaron en distinciones como premios, diplomas, aplausos o el enmarcar un cuadro que los y las participantes consideraron como significativas, pues evidencian 
En el carnaval

Se siente alegría participar en el carnaval (Hugo) Dibujé una carroza (Jesús)

Nos aplaude la gente (Hugo)

Ahí demostramos que sí podemos aunque sea con alguna dis_capacidad!! (Marcela)

La gente deja de lado la condición (Marcela)

Mis manos en el carnaval (María)

Muchas personas disfrutan del carnaval (Fabián) Dibuje la comparsa con la que salí (María)

En el carnaval han de pensar que somos cualquier persona

¡y somos cualquier persona! (Marcela)

Figura 4. Poema dadaísta esfera del amor la valoración social de sus capacidades y favorecen el referirse positivamente a sus cualidades y facultades logrando así su autoestima.

Por otra parte, consideramos de suma relevancia resaltar cómo una manifestación cultural como el Carnaval de Negro y Blancos, genera sentimientos de alegría, satisfacción y puede convertirse en el escenario idóneo para que las personas con dis capacidad se sientan "como cualquier persona (Marcela)" dentro de una sociedad. Y no sólo eso, sino que, además, las interacciones que se hilan también se perciben en condiciones de igualdad y respeto lo que favorece la seguridad sentida de poder llevar a cabo acciones durante la participación del carnaval que son reconocidas por los demás miembros de la sociedad como valiosas, lo que supera la percepción de la limitación y contribuye a la conquista de la autoestima. Por otra parte, el carnaval se convierte en un escenario para el disfrute y el encuentro con otras y otros que permite demostrar las capacidades diversas y las formas diferentes de ser y estar en el mundo. También, este evento cultural genera sentimientos de gratificación y alegría que no sólo se relacionan con el disfrute sino con la posibilidad de expresar "que sí podemos" lo que evidencia la autoconfianza ganada gracias a la participación en dichos eventos.

Sin duda, las personas con dis capacidad itinerantes en recorridos artísticos encuentran escenarios creativos y sensibles que posibilitan la valoración de sus capacidades. Posiblemente en estos escenarios se trasciende el estatus del artista, su dis capacidad o el interés productivo y comercial de la creación artística, para enfatizar como importante la expresión creativa que desencadena actos de reconocimientos considerados valiosos por las y los co-investigadores como son: las felicitaciones, los premios y los aplausos. Además, en dichos escenarios, des-cubren capacidades que les posibilitan alzar su voz para expresar que pueden ofrecer más de lo que se cree y asumir posiciones políticas que les permiten manifestar que cuentan y hacen parte de una

Entre haceres artísticos

El teatro me hace vivir (Marcela)

Nos felicitan (Hugo)

Me llena de emoción (Marcela)

Ensayamos para el día de la madre (Hugo)

Con el teatro podemos demostrar que damos más (Marcela)

Decimos que no nos tienen en una jaula (Marcela)

Decimos que queremos salir (Marcela)

Nos dan premios (Hugo)

Aprendí teatro mudo (Jesús)

Nos aplauden (Hugo)

Ha sido otra parte de nuestras vidas (Marcela)

Los aplausos lo dicen todo (Marcela)

Me dieron un diploma por participar en el carnaval (Hugo)

Vendí el cuadro de los girasoles (Hugo)

Voy a enmarcar todos mis diplomas (Hugo)

Figura 5. Poema dadaísta esfera del amor 
comunidad que debe valorar sus calidades y que no son seres humanos invisibles, encerrados en una jaula como lo expresa Marcela: "decimos que no nos tienen en una jaula...decimos que queremos salir".

Así pues, las y los jóvenes que hicieron parte de esta experiencia mencionaron reconocimientos que percibieron como valiosos como los diferentes premios que habían recibido gracias a su participación en eventos artísticos. Es interesante mencionar cómo un acto como el de enmarcar los cuadros elaborados en este caso por Hugo, se convierte en una experiencia de reconocimiento que genera sentimientos de satisfacción, pues le significa la exposición de su trabajo ante él mismo y los demás lo que favorece la consecución de su autoestima. Por otra parte, también el vender un cuadro como lo menciona Hugo se convierte en una evidencia de estima social que le hace sentir valorado por su labor.

\section{Tertulia reflexiva}

Esta investigación fue una experiencia profundamente sentida desde su construcción, desarrollo y culminación. Es por esto que, la manera de presentar la discusión pretende reflejar desde la investigación Basada en las Artes nuevas maneras de concebir la construcción de conocimiento. Por lo tanto, a continuación, se presenta un diálogo ficticio y algo teatralizado con Honneth, para entablar una conversación en la cual se cristalicen las innumerables reflexiones que se urdieron a lo largo de este proceso de investigación de una manera creativa. El diálogo simulado tiene lugar con la investigadora principal del estudio. Este fue el resultado.

Liliana: ¿Cómo está Dr. Honneth? Créame que hace mucho tiempo quería conocerlo. Le confieso que para mí no ha sido fácil comprender a profundidad sus planteamientos en torno a su Teoría del Reconocimiento, sin embargo, ha despertado un gran interés en mí al entretejerlas con las artes y el campo de la dis_capacidad. Esta es la razón por la que quiero compartirle mis reflexiones.

Dr. Honneth: Hola Liliana, también me da gusto conocerte y por supuesto gracias por el café. Te entiendo. Pero de lo que se trata no es de comprender a profundidad mi teoría, sino de que puedas matizarla de acuerdo con tus intereses y convicciones y re-crearla con lo que vayas encontrando en tus vivencias. Una teoría nunca es definitiva y está en constante evolución. Quisiera que me expongas el interés de tu estudio.

Liliana: De acuerdo. Mi interés se centró en generar reflexiones y creaciones en torno a las interrelaciones que se tejen entre Arte, Reconocimiento y Dis_capacidad, con la intención de que estos pigmentos permitan generar cuestionamientos frente al poder que tiene el arte para enfrentar el desprecio social y suscitar experiencias de reconocimiento y de reivindicación en las personas con dis_capacidad itinerantes por caminos artísticos; enmarcadas en una tensión permanente que busca des-atar sus luchas sociales para legitimar subjetividades excluidas y formas diversas de crear el mundo.

Dr. Honneth: Entiendo. Es interesante como mi Teoría del Reconocimiento haya llegado a permear el ámbito artístico y el de la dis_capacidad. Me interesa conocer las inferencias más relevantes que surgieron de este estudio. 
Liliana: Créame que para mí ha sido sorprendente. Le compartiré entonces las inferencias que emergieron de estas vivencias investigativas. Inicialmente encontré que, definitivamente el tejido de relaciones familiares, más específicamente con la madre, hermanos y hermanas, favorece la generación de experiencias de reconocimiento intersubjetivo para las personas con dis_capacidad itinerantes por rutas artísticas. Más aún, los haceres artísticos se convirtieron en el pre-texto para que las familias puedan generar acciones de reconocimiento (relacionadas en este caso con palabras de admiración, adjetivos positivos frente a su hacer y el pago de matrículas) que posibilitaron vivenciar algunas experiencias de reconocimiento recíproco con sus integrantes con dis_capacidad y demostrar su dedicación afectiva, el interés por su bienestar y la valoración de sus facultades artísticas, lo que les permitió a las y los participantes forjar su autoconfianza.

Dr. Honneth: Sí, en la familia, específicamente en las relaciones padre-hijo, se tejen lazos afectivos que, gracias a la dedicación afectiva que implica un interés por el bienestar del otro, se genera un reconocimiento recíproco que proporciona una valoración específica en las personas que les permiten alcanzar su seguridad emocional o, en otras palabras, su autoconfianza en la experiencia intersubjetiva del amor, como lo explico en mi libro Teoría del Reconocimiento de 1997. Quisiera saber, a propósito de tus hallazgos, cuáles fueron los elementos relevantes para ti.

Liliana: Para mí, es relevante cómo, las artes, más cercanas a la autoexpresión y al afecto y un poco más distantes de la técnica, fortalecen las relaciones dentro de la familia y la autoconfianza mediadas por experiencias de reconocimiento que se enlazan al hacer artístico de las personas con dis_capacidad. Al parecer, el arte se convirtió en una "evidencia" de las capacidades de las personas con dis capacidad originando experiencias de reconocimiento intersubjetivo que les permitió ganar la confianza en sí mismos y en sí mismas.

Por otra parte, en este estudio observé que las personas participantes dan igual importancia a las relaciones con la familia, que a los lazos afectivos que se urden con los amigos y amigas, incluyendo aquí a los docentes de la Fundación, lugar en el que realicé mi estudio. Esta importancia radica en que las relaciones de amistad tienen un carácter de aceptación de la persona como ser humano diferente pero igualmente valioso que los demás. Es tal la relevancia de estos vínculos, que los amigos y amigas son considerados como parte de la familia, pues en estas dinámicas relacionales, también se percibe una dedicación afectiva y un interés por el bienestar del otro u otra. Nuevamente los haceres artísticos proporcionan el escenario para que los vínculos afectivos se fortalezcan y la creación artística se convierta no sólo en un producto, sino en el proceso mediante el cual se construyen afectos para la realización personal.

Dr. Honneth: Espera, los lazos de amistad yo los considero dentro de la esfera del amor, sin embargo las relaciones con los docentes hacen parte del ámbito institucional, ¿cómo entender esa permeabilidad entre la esfera del amor y la ley?

Liliana: Pienso que para las personas que hacen parte de este estudio, la familia no se conforman necesariamente a través de designios biológicos, sino que tiene que ver con aquellas relaciones significativas, de afecto y de reconocimiento recíproco que se tejen en la interacción cotidiana y, que en este caso, son mediadas por la creación artística. Por lo tanto, no es extraño que incluso las y los docentes, y no 
solamente los pares con o sin dis_capacidad, sean considerados como parte de la familia, pues en sus vínculos de interacción recíproca también están presentes la dedicación afectiva, el interés por el bienestar de otro u otra y la aceptación. De manera que, dicho vínculo trasciende las relaciones que se establece con la institución para llegar a la relación que se establece entre seres humanos. Además, creo que la aceptación, es un aspecto relevante para las personas con dis_capacidad de este estudio, pues esta no implica la resignación sobre lo que la persona puede o no llegar a ser, sino, por el contrario, la valoración frente a lo que la otra persona es, lo que implica superar las expectativas sobre lo que se debe ser y estimar a la otra persona por sus propias cualidades, no por las que se espera que se tenga. Esto último, quizá sea lo que frecuentemente ocurre en las familias, y particularmente con los padres, quienes construyen expectativas frente a sus hijos e hijas y, que en el caso de las personas con dis_capacidad, rápidamente son disueltas generando ambivalencia frente a lo que se esperaba y lo que se es.

Dr. Honneth: Con tu explicación, encuentro concordancia con mis planteamientos, por eso ubico dentro de la esfera del amor las relaciones con los amigos y amigas, pues considero que éstas puede generar experiencias de reconocimiento intersubjetivo en las personas que, vinculadas con la dedicación afectiva, puedan contribuir a alcanzar su autoconfianza. De otra parte, los maestros suelo ubicarlos en la esfera de la ley, pues ellos hacen parte de las instituciones, sin embargo es interesante pensar que las relaciones significativas que se construyen con ellos y ellas quizá puedan trascender o complejizar los contextos institucionales.

Liliana: Precisamente Doctor Honneth, en los contextos institucionales que tienen que ver con la esfera de la ley encontré elementos interesantes. En cuanto a las instituciones que se sitúan en el ámbito de lo público, en este estudio las personas privilegiaron la Fundación Luna Arte. Esta organización a partir de la creación artística, la autoexpresión y el afecto ha garantizado el derecho que tienen las personas con dis_capacidad, como lo menciona la Convención de los Derechos de las Personas con Dis_capacidad de 2006, a participar, en igualdad de condiciones con las demás, en la vida cultural y artística asegurando que puedan desarrollar y utilizar su potencial creativo para el beneficio propio y el de la sociedad en general (Palacios. y Bariffi, 2007). De manera que, el acceso a las manifestaciones artísticas se constituye en un derecho fundamental, y que las personas pertenecientes a esta Fundación han podido disfrutar en igualdad jurídica a las demás miembros de la sociedad. No obstante, podría decirse que la Fundación ha ido más allá, pues ha garantizado, no sólo que las personas con dis_capacidad tengan acceso a actividades artísticas y culturales, sino que han luchado porque sean ellas mismas quienes presenten propuestas artísticas desde el teatro, la danza, la pintura, la música que les permitan insertarse en el ámbito artístico, ser parte de éste y aportar al desarrollo de la tradición cultural de la ciudad de San Juan de Pasto.

Dr. Honneth: Entiendo lo que me comentas y puedo percibir algunos matices de mi teoría en lo que acabas de mencionar. Es importante lo que plantea la Convención de los Derechos de las Personas con Dis_capacidad al declarar que la participación en igualdad de condiciones con las demás personas en la vida cultural y artística es un derecho que no puede pasarse por alto. ¿Cuál crees que sea el principal efecto de esta protección y lucha por el derecho a participar y hacer parte de la vida artística de su región en las personas que conformaron tu investigación? 
Liliana: Considero que, de acuerdo con su teoría, este agenciamiento puede devenir en la consecución de su autorrespeto, ya que perciben que están disfrutando de las manifestaciones artísticas como cualquier persona de su comunidad, por lo tanto, pueden percibirse, no sólo como sujetos y sujetas de interacción legítimos e iguales jurídicamente a los demás al ser garantizados sus derechos, sino como seres humanos plenamente valiosos para su sociedad logrando respetarse a sí mismo o a sí misma debido a que merecen el respeto de su prójimo, desactivando la marginación social.

Dr. Honneth: ¿A qué haces referencia con desactivar la marginación social?

Liliana: A que al restituir el derecho de las personas con dis_capacidad, en este caso específico, al disfrute, desarrollo y participación de los haceres artísticos implícitamente significa que se les consideran, en igual medida, responsables y estimados como a los demás miembros de la sociedad. Re-aparece así, un significado emancipador que cuestiona aquellas concepciones de la dis_capacidad que aíslan y marginan, para reemplazarlas por las que generan solidarida $\bar{d}$ y dignidad puesto que, como lo expresa Mabila (2002) es en la cultura donde se pueden ir desaprendiendo estereotipos y cambiando las actitudes negativas y la representación incorrecta acerca de las personas con dis_capacidad.

Dr. Honneth: Comprendo. Me gustaría conocer ahora tus precisiones acerca en la esfera del logro.

Liliana: En la esfera del logro es donde encuentro algunas disonancias con su teoría. Me explicaré. Usted planteó en 2011, que la apreciación social de una persona se mide según su aportación a la sociedad en forma de un trabajo formalmente organizado. Lo que entiendo al respecto, es que el valor que una sociedad otorga a un ser humano está dado por el aporte que él o ella hace a su sociedad a través de su trabajo formalmente organizado. Sin embargo, en el presente estudio, a pesar de que los haceres artísticos, como el caso de la pintura, se percibieron como una posibilidad laboral, esta no fue la única forma en que las personas con dis_capacidad se sintieron valoradas socialmente. Este colectivo sintió que sus haceres, durante la participación en tradiciones culturales como el Carnaval de Blancos y Negros y en prácticas artísticas como la danza, el teatro, la música, la pintura presentadas en diferentes escenarios culturales, fueron merecedores de valoración social lo que se demostró, no en una retribución económica, sino en aplausos, diplomas, premios, felicitaciones y hasta en el enmarque de sus pinturas, que se convirtieron en la certeza que la sociedad estaba reconociendo sus capacidades y aportaciones como valiosas, lo que favoreció la conquista de la autoestima y la superación de la percepción de limitación. Las artes como lo he expone Mabila (2002) favorecen que las personas con dis_capacidad asuman posturas políticas y manifiesten que cuentan y hacen parte de una comunidad que debe valorar sus capacidades individuales y sus contribuciones desde su propia realización personal.

Dr. Honneth: Digamos que de manera simplificada, en 2011 mencioné que la esfera del logro tiene que ver con la apreciación social del rendimiento y de las capacidades individuales. Considero que las personas necesitan además del amor y del reconocimiento jurídico la valoración social de sus cualidades que les permitan referirse a sí mismas positivamente, lo cual tiene concordancia con tus hallazgos, ya que la valoración social percibida por las personas con dis_capacidad en la participación en 
la vida artística, les permitió fortalecer su autoestima. Sin embargo, las capacidades y actuaciones de las personas pueden ser intersubjetivamente estimadas en la medida en que su forma de autorrealización (en este caso mediada por las artes) contribuye a la consecución práctica de los objetivos definidos de una sociedad, por lo que te pregunto ¿cómo pueden las artes, desligadas de un trabajo formalmente organizado, contribuir al logro de los objetivos de la sociedad en la que estas personas viven?

Liliana: Procurando la autorrealización, expansión vital de cada ser humano y, por ende, el desarrollo cultural de la región. Me explicaré. Como usted lo plantea en 1997, la estima intersubjetiva está dada en la medida en que la forma particular de autorrealización de una persona aporta a la sociedad; y creo que aquí está la respuesta su pregunta. Si no me equivoco, usted hace énfasis en que cada persona tiene su propia forma de autorrealización y que el horizonte de valoración que establece una sociedad debe permanecer abierto a los diferentes tipos de autorrealización, por lo tanto, si la realización de un colectivo de personas es transitar por sus caminos artísticos, participar y aportar con sus haceres a la vida cultural, la sociedad debería abrir su horizonte de valoración a este tipo de autorrealización particular desligada de un trabajo formalmente organizado, ya que las personas con dis_capacidad particularmente en este estudio, encuentran en los escenarios creativos posibilidades para el fortalecimiento de lazos afectivos, la restitución de derechos culturales y la apreciación de sus facultades, lo que favorece la conquista de su autoconfianza, autorrespeto y autoestima respectivamente. Además, si entendiéramos la sociedad como un sistema vivo, en el cual todas sus partes se encuentran interrelacionadas, entonces, la realización particular de una sola persona perteneciente a dicho sistema, contribuiría en la realización o desarrollo del mismo.

Dr. Honneth: Desde tus comprensiones ¿Qué pasaría si una sociedad sólo reconociera a aquellos tipos de autorrealización vinculados a un trabajo formalmente organizado?

Liliana: Pues que seguramente, de acuerdo a lo planteado en su teoría, no podría esperarse que una persona tenga intenciones de procurar la realización de otra que no esté relacionada con un trabajo formalmente organizado porque no tendrían intereses comunes, lo que implicaría establecer relaciones solidarias sólo con ciertas personas; aquellas que desde su trabajo puedan aportar a la sociedad. Esto sin duda, conllevaría a negar la estima social a muchas personas con dis_capacidad, y sobre todo de aquellas que, como en este caso, encuentran en los haceres artísticos una posibilidad de descubrir, explorar, demostrar sus capacidades y aportar al desarrollo de su sociedad, teniendo en cuenta que en muchas ocasiones a este colectivo no se lo define por sus cualidades y capacidades sino por sus limitaciones que los inserta en lo improductivo y lo no competitivo.

Por mi parte, estoy convencida que la estima social de cualquier persona no puede condicionarse ni medirse, de manera que la valoración por parte de su entorno tiene que evidenciarse al reconocer formas de autorrealización diversas que pueden aportar de diferentes maneras al desarrollo de la sociedad, quizá no necesariamente en un desarrollo económico sino en un desarrollo humano.

Dr. Honneth: Como lo dije anteriormente, las teorías están en constante construcción y quizá lo más valioso de ellas es que suscitan un diálogo de saberes que sin duda aportan a una comprensión más compleja de nuestras vivencias. 
Liliana: El compartir diferentes puntos de vista es profundamente enriquecedor.

Dr. Honneth: Bueno, se acerca la tarde. Te agradezco mucho tu invitación y la pasión con la que me has compartido tus reflexiones. No quisiera que termináramos esta conversación sin que me cuentes ¿qué te deja este encuentro?

Liliana: Este encuentro realmente ha sido muy significativo para mí. Le agradezco mucho su interés. Sé que hay muchas cosas que restarían por decir, por su puesto más en su caso que en el mío, pues he sido yo, quien no ha parado de hablar. Pero a pesar de esto, creo que esta conversación me ayudó a poner en claro mis ideas, mis reflexiones y planteamientos, y así, poderlos comunicar y debatir. Estoy segura que sin su ayuda y disposición quizá no hubiera podido descifrar aquellos laberintos en los que a veces se convierten los pensamientos y, más aún, cuando se relacionan con teorías complejas y fructíferas como la suya. Sinceramente Dr Honneth para mí ha sido un honor poder compartir con usted aquellas reflexiones que recorrían continuamente mi cabeza. Le agradezco su escucha atenta y su total disposición para comunicarme sus apreciaciones. Esta fue una tarde invaluable para mí. Muchas gracias.

Dr. Honneth: Gracias a ti.

\section{Finalizando el recorrido para andar nuevos caminos}

De acuerdo con las narraciones visuales y textuales de las y los co-creadores de esta investigación, se podría decir que los haceres artísticos sí favorecen experiencias de reconocimiento recíproco desde la familia, los amigos al fortalecer los lazos afectivos y la valoración de capacidades, lo que permitió a las y los participantes forjar su autoconfianza en el marco de sus relaciones significativas. De manera que, los haceres artísticos son un motivo para generar acciones de reconocimiento que posibilitan vivenciar la dedicación afectiva, el interés por el propio bienestar y la valoración de las facultades artísticas en la experiencia intersubjetiva del amor. Así, la creación artística es más que un producto, un objeto o una mercancía, sino que se convierte en un camino en el cual se construyen afectos para la realización personal, en este caso específico, de la población con dis_capacidad. En este estudio, también encontramos que el arte es y debe ser considerado un derecho fundamental para las personas con dis_capacidad, trascendiendo el estatus del artista, el interés productivo, laboral y comercial de la creación, para destacar como relevante la voz de la propia subjetividad creadora e históricamente excluida. Es por esto que, para las personas que conformaron este estudio, el hacer parte y disfrutar de manifestaciones artísticas se constituyó en una oportunidad para la consecución de su autorrespeto al percibirse que lo hacen en igualdad de condiciones que cualquier otra persona de su comunidad, logrando considerarse seres humanos plenamente valiosos debido a que merecen el respeto de su prójimo.

Es necesario resaltar que, no sólo el participar sino el contribuir al desarrollo de la vida artística y cultural de una región, contribuye a la valoración social de las personas con dis_capacidad, al realce de sus capacidades y a agenciar sus propias luchas por el reconocimiento. En otras palabras, las tradiciones culturales como el Carnaval de Negros y Blancos y haceres artísticos como la danza, el teatro, la música, la pin- 
tura, forman escenarios propicios para que se aprecien las cualidades y facultades de esta población de forma simétrica, lo que les demostró la valoración social por parte de las personas de su región y el reconocimiento de sus aportaciones como valiosas, favoreciendo la conquista de su autoestima

Ahora bien, teniendo en cuenta que esta investigación muestra la relevancia que tiene el arte para las personas con dis_capacidad, es imperioso tomar conciencia de que el tema del arte es un tema trascendental dentro de los estudios humanísticos. Por lo tanto, es necesario promover más investigaciones en el campo artístico y, específicamente, indagar sobre la educación artística que reciben las personas con dis_capacidad y la promoción en la comunidad a la que pertenecen.

Finalmente, es necesario resaltar que para las personas co-creadoras de este estudio, el trabajo con los bodymap posibilitó la exploración y las expansión de experiencias artísticas que les permitió des-cubrir otros tipo de sensaciones y emociones que las y los llevaron a transitar por caminos de reconocimiento desde sus formas diversas de ser en el mundo. De manera que, esta vivencia es una invitación a las y los investigadores a que se dejen cautivar por aquellas metodologías artísticas que favorecen otro tipo de exploraciones dentro del ámbito académico y que se erigen como una alternativa en la cual, las emociones, sensibilidades y creatividades son el foco desde el cual emergen un conocimiento vivo.

\section{Referencias Bibliográficas}

Gastaldo, D. et al. (2012): "Body-Map Storytelling as Research: Methodological considerations for telling the stories of undocumented workers through body mapping" (en linea). Canadian Institutes of Health Research -Canada, Toronto http://www.migrationhealth.ca/ sites/default/files/Body-map_storytelling_as_reseach_LQ.pdf

Honneth, A. (2011). La sociedad del desprecio. Madrid: Editorial Trotta.

Honneth, A. (1998). "Entre Aristóteles y Kant. Esbozo de una moral del reconocimiento". Logos. Anales de metafísica. 1: 17-37, Universidad Cornplutense de Madrid. Disponible en: http://revistas.ucm.es/index.php/ASEM/article/viewFile/ASEM9899110017A/16713

Honneth, A. (1997). La lucha por el reconocimiento. Por una gramática moral de los conflictos sociales. Barcelona: Crítica Grijalbo.

Mabila, M. (2002). "El elemento político de la discapacidad en las artes y la cultura: Una entrevista con Mandla Mabila". Revista electrónica bi-mensual sobre noticias y opiniones internacionales relacionadas al tema de la discapacidad. 13. Disponible en http:// www.disabilityworld.org/04-05_02/spanish/artes/mandla.shtml

Marín, R. (2011). "Las investigaciones en educación artística y las metodologías artísticas de investigación en educación: temas, tendencias y miradas". Educação, Porto Alegre. 34 (3): 271-285. Disponible en: file://C:/Users/lili/Downloads/9515-35552-1-PB\%20 (1).pdf

Palacios, A. (2008). El modelo social de dis_capacidad: orígenes, caracterización y plasmación en la convención internacional sobre los derechos de las personas con discapacidad. Madrid: CERMI.

Palacios A. y Bariffe, F. (2007). La discapacidad como una cuestión de derechos humanos. Una aproximación a la convención internacional sobre derechos de las personas con discapacidad, Madrid: Ediciones Cinca, Colecciones CERMI-Telefónica 
Roldán, J., y Marín, R. (2012). Metodologías artísticas de investigación en educación. España. Málaga: Ediciones Aljibe

Springgay, S. et al. (2005): “A/r/tography as Living Inquiry Through Art and Text". Qualitative Inquiry. 11 (6): 897-912. 